\title{
El nacimiento de un observador social Charles Darwin en San Salvador de Bahía (29/2-18/3/1832)
}

Recibido: 16.03 .18

Aprobado: 21.09 .18
Luis Arana Bustamante

Universidad Nacional Mayor de San Marcos laranab@unmsm.edu.pe

\section{RESUMEN}

Este trabajo — el primero de dos proyectados sobre Darwin en Brasil— empieza el estudio de la formación del punto de vista como observador social —y sociológico— del naturalista británico a través del examen de su primer contacto con la realidad social sudamericana en San Salvador de Bahía, Brasil. Puede decirse que este aspecto de su formación —muy poco estudiado - empezó en el Brasil, país donde se ha estudiado poco la visita de Darwin, aparentemente debido al rechazo que produjeron en él la esclavitud y el sistema esclavista. Charles Darwin residió en ese país un total de cuatro meses y tres días entre febrero y julio de 1832. Usamos como fuente principal el llamado Diario del Beagle (Darwin [1831-1836]), subutilizado como fuente en la investigación sobre la personalidad histórica del naturalista británico.

Palabras Clave: Charles Darwin; viaje del Beagle; ciencia social latinoamericana; historia de la ciencia en Latinoamérica; Brasil siglo XIX.

\section{The naissance of a social observer. \\ Charles Darwin in San Salvador de Bahia (feb.,29-mar.,18, 1832)}

\begin{abstract}
This article, first of two projected about Darwin in Brazil, starts the examination of the making of Charles Darwin as social — and sociological_ observer through examination of his first contact with South American social realities in San Salvador de Bahia, Brazil. It can be said that this process, not much studied in Darwinian research, begun in Brazil, notwithstanding the more or less brief residence of the British naturalist in this country (four months and three days between February and July, 1832). Brazilian historiography has not researched Darwin's presence in this country because his plain opinions against the slavery system. We used the Beagles's Diary (Darwin [1831-1836]), as principal historical source in this aspect of our Darwin research.
\end{abstract}

Keywords: Charles Darwin; Beagles's voyage; Latin American social science; history of science in Latin America; Brasil in XIXth century. 
Brasil debe, en todo aspecto, ser considerado como un país nuevo... Ningún país bajo el cielo... está mejor acondicionado que Brasil tanto para hacerse a sí mismo como a sus aliados grande y rico.

J. Turnbull, A Voyage Round the World... [1813], IV: $30^{1}$

Si a lo que la naturaleza ha otorgado al Brasil el hombre añade sus justos y propios esfuerzos, ¡de qué [gran] país pueden los habitantes alardear! Pero la mayor parte está bajo un estado de esclavitud, y donde este sistema es mantenido con un completa detención de la educación, la principal fuente de las acciones humanas, esto causa lo que puede ser esperado...

C. Darwin, Charles Darwin's Beagle Diary, [1831-1836] 1989: 46, mi traducción

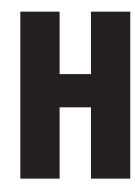
a sido señalado con justicia que el segundo viaje (1831-1836) del H.M.S Beagle - junto con las impresiones del naturalista de a bordo- merecería en su totalidad la atención de los historiadores también como testimonio de una época en que Inglaterra empezaba a preparar su dominio mundial -el principio de la denominada Pax Britannica, que duró de 1815 a 1918-. Este dominio dell imperio británico sucedió en gran parte a través del gradual control del comercio atlántico y mundial, abriendo vastos mercados para sus propias mercancías. ${ }^{2}$ El historiador John Darwin señala que desde los 1830, los británicos "gradualmente transformaron su legado expansivo de guerra y mercantilismo en un sistema mundo...» (2009:23). ${ }^{3}$ Así, aquellos que diseñaron la extensión del territorio colonial británico

...buscaron primero las regiones donde se temía una menor resistencia, o donde los británicos comandaban ya las rutas geográficas principales (idem, 24).

1 Esta y todas las citas textuales de las fuentes originales de y sobre Darwin en inglés colocadas a continuación consisten en mis traducciones, e introduzco palabras entre corchetes donde resulta necesario para aclarar el sentido de las frases.

2 Sobre los orígenes y el primer período del dominio británico mundial, ver Eldridge, ed. (1984), Bayly (1989), Cain y Hopkins, eds. (2002), Stockwell, ed. (2008), Darwin (2009:1-63, n.d.). Los trabajos de Browne (1989, 2005), Desmond y Morris (1991) y Taylor (2009) sitúan bien el viaje del Beagle y la personalidad de Darwin en el contexto de su época.

3 Para este autor la década de 1830 marca la frontera en la constitución de lo que denomina -más que un imperio propiamente dicho- el sistema mundo británico; 1832 fue el primer año en que más de 100,000 británicos partieron a destinos fuera de Europa. Seńala que la Royal Geographical Society se fundó en 1830 (2009:41, 48).
Ello sucedió para este autor porque, si bien la Gran Bretańa victoriana era un estado poderoso, no era hegemónico por falta de un poder militar terrestre. Así, fue muy importante

...la presión ejercida por las viejas redes y lobbies que administraban los intereses externos británicos y las nuevas que se alzaron para promover la empresa comercial, de búsqueda de tierra, humanitaria, misionera o científica (idem).

El colapso de España bajo la invasión napoleónica y la emigración de la corte portuguesa a Brasil en 1808 - con su consecuente colocación del reino de Portugal como estado cliente de Inglaterra— habían abierto

la costa atlántico sur a la influencia marítima británica en Brasil y La Plata y (con la ocupación de las islas Falkland en 1833) le dieron una guarnición que controlaba el Cabo de Hornos (idem).

Así, Gran Bretaña era entonces el único poder europeo que podía establecer una influencia realmente mundial, y para la diplomacia de Lord George Canning —ministro de asuntos exteriores de 1822 a 1827 - era preciso explotar esta ventaja y restringir a los vecinos europeos de los británicos a los asuntos del continente europeo. En 1826 Canning declaró:

Decidí que si Francia tuviese España, no debía ser España 'con las Indias'. Desperté al Nuevo Mundo a su existencia para restablecer el equilibrio en el Viejo (citado en Waddell 1985:225).

Por eso era urgente establecer relaciones amistosas con los nuevos estados independientes en Latinoamérica (idem). Canning dijo ese mismo año: "Hispanoamérica es libre; y si nosotros no manejamos mal la situación, es inglesa» (citado en idem).

En efecto, hacia la época del segundo viaje del Beagle a Sudamérica, ingleses, franceses y norteamericanos mantenían flotillas de barcos de guerra apostadas en el Pacífico, con la misión de observar cercanamente la vida comercial y política de los países recién emancipados y dar protección a sus connacionales allí residentes, cada vez más numerosos. Es por ello que en esta carrera por el control tuvo un papel de primer orden la actividad naval, de exploración y de resguardo de los intereses británicos de la Marina de ese país. 


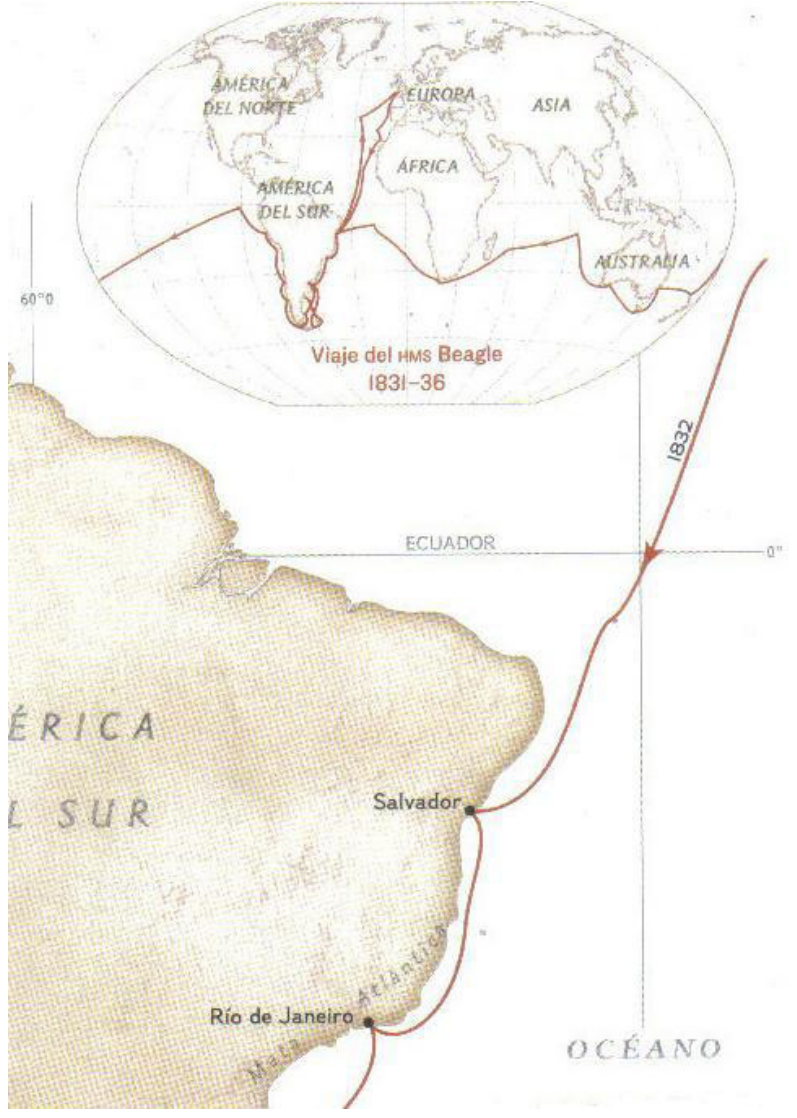

Figura 1. Detalle de mapa esquemático del segundo viaje del HMS Beagle alrededor del mundo. Dibujo de Charles Berry, tomado de Quanmen (2009).

\section{El contexto amplio del viaje}

La principal biógrafa moderna del naturalista Charles Darwin, la historiadora de la ciencia británica Janet Browne, señala que el viaje del Beagle tuvo implicancias políticas y económicas significativas en términos de la época. Expediciones como ésta debían satisfacer complejos propósitos administrativos y nacionales dentro de los cuales «...la exploración geográfica y la retórica del descubrimiento no eran más que una parte — si bien esencial— de la infraestructura en desarrollo del imperio" (Browne 2005:256). El Almirantazgo británico se encontraba comprometido entonces en una labor de modernización y tecnificación de la propia Marina. El hidrógrafo-jefe de la Marina Real, Francis Beaufort —-formado en Matemáticas en Cambridge y con numerosos contactos allí - pretendía transformar al capitán de la segunda expedición del Beagle, Robert FitzRoy (1805-
1865), en una herramienta de esta modernización. Aristócrata de origen y hombre de la corte, FitzRoy había recibido una instrucción privilegiada, en ciencias exactas y climatología, en el Royal Naval College de Porthsmouth —entre cuyos graduados se encontraba nada menos que Alexander von Humboldt-, donde FitzRoy se graduó con medalla de oro. ${ }^{4}$

El deseo del Almirantazgo de cartografiar América del Sur tenía así como motivo

...tomar decisiones bien informadas sobre operaciones navales, militares y comerciales a lo largo de la costa inexplorada del sur de Buenos Aires y hacer posible para Gran Bretaña el establecimiento de apoyos firmes en aquellas áreas... [... ¿ Había allí yacimientos de oro y diamantes como había en Brasil? Sabían que había guano, materia prima de la vasta industria de los fertilizantes de la Gran Bretańa de comienzos del siglo xix y unas salinas importantes. ${ }^{5}$

Las naves de la Marina británica eran parte integrante de una red colonial, así un barco de la Marina era además

$[u] n$ emisario, una despensa flotante de noticias y tendencias de la Gran Bretańa, el repartidor de cartas y periódicos de la patria... un vehículo para traer pasajeros puntuales... un lugar para las fiestas oficiales y las recepciones, siempre vivo para la sociedad colonial de ultramar (idem, 258).

Así, el segundo viaje del Beagle debía explorar las posibilidades de explotación de áreas poco ocupadas de Sudamérica como Patagonia y Tierra del Fuego y mapear con cuidado las costas de naciones recientemente independizadas de la costa del Pacífico. El comercio exterior de esas naciones —Chile y Perú, antes inclui-

4 Ver Browne (2005:255), Passetti (2014). Pero el carácter misantrópico y tendencias depresivas de FitzRoy malograrían estas intenciones puestas en él por el alto mando. Esta investigación nos ha dado la impresión de que FitzRoy tenía intenciones particulares en el segundo viaje del Beagle: la explotación de posibles yacimientos metalíferos hasta entonces desconocidos en el extremo sur del continente. Sin embargo, esta combinación de servicio público e interés privado no era rara, sino fue característica de quienes edificaron el sistema mundo británico -que sin embargo se autoconcebía como un imperio-.

5 Idem, 257. Por otro lado, Browne señala también la necesidad en esta época de Gran Bretaña de "lazos comerciales más definidos» con Sudamérica para darse más peso en la balanza de poder europea, y asimismo la necesidad de protección de unas ciento cincuenta millones de libras de dinero inglés invertido en diversas operaciones especulativas en Sudamérica hacia la época del viaje (ibidem). 
das en el virreinato del Perú- estuvo formalmente controlado, como se sabe, durante tres siglos por el monopolio comercial español, si bien era quebrado sistemáticamente desde el siglo XvII por el contrabando de los holandeses y luego de los ingleses y franceses.

Desde esa época estas naves europeas doblaban el Cabo de Hornos y colocaban - a cambio de plata incluso en vajillas - productos europeos - y luego británicos - más baratos de contrabando en puertos, bahías y ensenadas distintos a Lima, quebrando el monopolio del comercio en Chile y Perú con los comerciantes primero de Sevilla y luego de Cádiz. La independencia de las naciones sudamericanas significó, como se sabe, el inicio de la participación política formal y el ingreso oficial del comercio británico en la región (v. Flores Galindo 1979).

Las circunstancias de gestación del segundo viaje del H.M.S. Beagle a Sudamérica -1831-1836-, aunque nada sencillas, son en su mayor parte conocidas. ${ }^{6}$ El Beagle — nombre de una variedad de pequeño perro de presa inglés - era un brig o bergantín militar reconvertido en una barque o bark de reconocimiento, que hacía en Inglaterra sobre todo el llamado cabotaje costero. Era poco apto para la navegación por alta mar y en realidad no se alejó mucho de la costa al recorrer el continente sudamericano. En Sudamérica su labor de reconocimiento costero la efectuó con siete botes auxiliares y con naves contratadas (Thomson 1975).

$\mathrm{Su}$ viaje a Sudamérica empezaba en el Brasil no por casualidad. En Río de Janeiro residía la comandancia de la 'station of South America', como se llamaba a la sub-flota británica que recorría permanentemente los puertos de este subcontinente, y que estaba en esta época bajo el mando del Almirante Sir Thomas Baker. El Beagle se abasteció y preparó en Río antes de empezar su labor de mapeo en las inhóspitas tierras situadas más al sur y allí se completó el primer contacto del naturalista Darwin, nacido en 1809, con la realidad natural y social sudamericana. ${ }^{7}$ Pero este primer contacto se inició en realidad en San Salvador de Bahía, donde llegó primero el Beagle. Darwin permaneció en Bahía entre el 29 de febrero y el 18 de marzo de 1832 .

6 Ver Keynes (1988) y Browne, op. cit.

7 Luego FitzRoy eligió Montevideo como puerto de base para sus operaciones más al sur.

\section{Darwin en Sudamérica y sus estudiosos}

\author{
El viaje del Beagle ha sido de lejos el \\ acontecimiento más importante en mi vida \\ y ha determinado toda mi carrera. [...] \\ ...[D] ebo al viaje el primer entrenamiento o \\ educación real de mi mente. \\ Darwin, [1876] 1958:77.
}

En realidad es difícil aislar al segundo viaje del Beagle y las actividades realizadas en él de la coyuntura de las naciones sudamericanas a principios del siglo XIX y de la variedad de intereses económicos y políticos de la Inglaterra de ese tiempo. Sin embargo, no es muy frecuente que sus biógrafos y los historiadores de la ciencia traten las observaciones políticas y sociales del joven Charles Darwin.

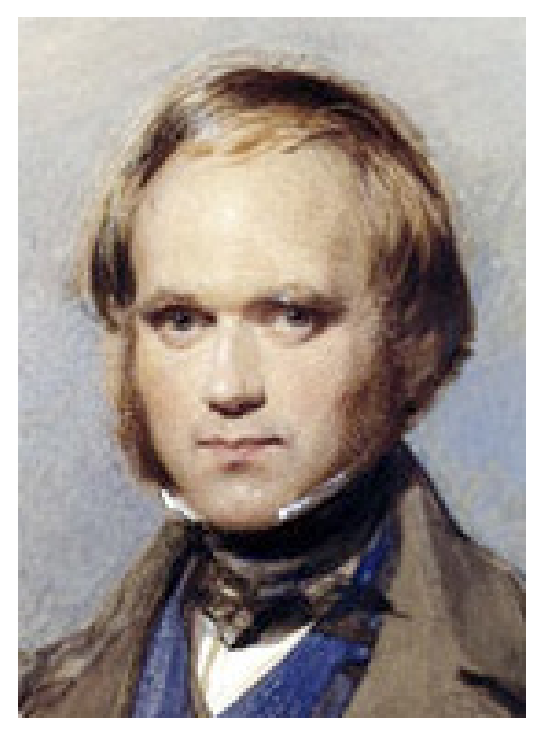

Figura 2. Detalle de acuarela de G. Richmond mostrando a Darwin en 1840 - a los treintiún años-. Retrato para su matrimonio con su prima Emma Wedgwood ese mismo año, conservado en la casa-museo de Darwin en Down, Kent. Tomado de Leakey and Levin $(1977: 38)$

Éste partió a Sudamérica con sólo 22 años, retornó a Inglaterra a los 27 y sus biógrafos han notado cómo maduró de modo notable, tanto intelectual como psicológicamente, durante la travesía del Beagle. ${ }^{8}$ El foco del interés de los estudiosos del viaje está siempre puesto en sus observaciones y reflexiones sobre la historia natural y geología durante el mis-

8 Él mismo interpretó esto en el Brasil como un efecto del clima y ambiente tropical sobre la propia mente, que parecía funcionar allí «más afinadamente» (Darwin [1831-1836]1988: 68). 
mo, pues, como se sabe, en Sudamérica Darwin puso a prueba ni más ni menos que las teorías entonces recientes del naturalista escocés Charles Lyell (17971875) sobre la probable evolución geológica de la tierra. A la luz de estas ideas el naturalista hizo observaciones geológicas y se planteó problemas de tal naturaleza sobre la flora y sobre todo la fauna actual y extinta sudamericanas, que le llevaron a empezar a columbrar al final del viaje - como se sabe ahora por el desciframiento y examen cuidadoso de las libretas de apuntes del mismo- la teoría de la evolución de las especies por selección natural. ${ }^{9}$

Tal programa del joven naturalista durante el viaje del Beagle ha sido desde luego más que suficiente para casi tres generaciones de estudiosos de su vida y obra. Ahora bien, empezando a estudiar los materiales producidos por él durante el viaje he visto confirmado lo antes señalado por varios observadores: cómo, comparativamente, se han dejado de estudiar los aspectos sociales, de historia social e incluso cultural del viaje.

\section{La fuente principal aquí empleada}

En cuanto a los apuntes mismos de Darwin durante el viaje, fueron tomados primeros en libretas que le acompañaban en el terreno y que luego él transcribía y ampliaba en otros documentos, y obviamente no fueron pensados para su publicación. Luego desarrollaba parte de estos apuntes en su Diario, casi siempre de inmediato. Pero en muchas ocasiones recién después de dos o tres meses encontró Darwin tiempo suficiente para ampliar las observaciones anotadas en las libretas, como ha notado Norah Barlow — nieta del naturalista, redescubridora del Diario y su primera editora en 1933 - en el estudio preliminar de su primera edición (Barlow 1933). Ella lo bautizó además en inglés como el Beagle’s Diary, para diferenciarlo del libro de viajes, impreso dos veces en 1839, una más al año siguiente y luego reescrito en la versión definitiva de 1845 , el llamado usualmente Beagle’s Voyage. ${ }^{10}$ El Diary, narración original del viaje

9 Ver Sulloway (1982) y la abundante investigación subsiguiente sobre el tema, que ha dilucidado ya lo principal del prolongado proceso del origen de su teoría. Un resumen en el libro de Browne (2006).

10 El libro de viajes fue editado por primera vez en agosto de 1839 en la imprenta de Henry Colburn, Londres, como volumen III de la
- en realidad un manuscrito sin título- fue escrito por Darwin en hojas sueltas y enviada en paquetes, por partes, a sus hermanas, durante el mismo, para ser leído a los miembros de la familia - y a los primos Wedgwood-. Se conserva en la casa-museo de Charles Darwin en Down y permanece inédito en castellano. ${ }^{11}$

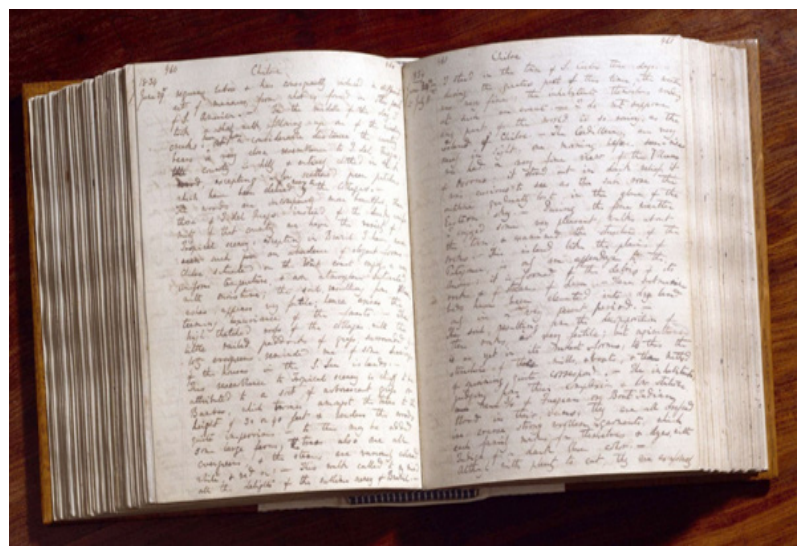

Figura 3. Fotografía del manuscrito original del Diary de Charles Darwin tal como se conserva en la casa museo de Darwin, Down. Foto tomada del sitio web de la casa museo en Kent: www.englishheritage.org.uk

Narrative of the surveying voyages of His Majesty's Ships Adventure and Beagle, between the years 1826 and 1836, describing their examination of the southern shores of South America, and the Beagle's circumnavigation of the globe, (4 vol.). El volumen I, tratando el primer viaje, fue editado por Robert FitzRoy basándose en los apuntes del trágicamente fallecido capitán P. Parker King. El volumen II, sobre el segundo viaje, es de autoría de Robert FitzRoy y trae un volumen de apéndice de información náutica y documentos sobre el viaje. El tercer volumen, de Charles Darwin, trae como subtítulo en esta primera impresión de 1839 Journal and Remarks, 1832-1836 ("Diario y Comentarios, 1832-1836»). Ante la mayor venta del tercer volumen, el impresor Colburn lanzó una segunda reimpresión idéntica excepto en el título, cambiado a Journal of Researches into the Geology and Natural History of the various Countries visited by H.M.S. Beagle under the command of Captain FitzRoy, R.N. [Royal Navy] from 1832 to 1836. Un tercera reimpresión fue hecha en 1840 . Ver sobre el tema de las ediciones del Journal of Researches... el estudio preliminar de R.D. Keynes en la Introduction, xi-xxiv, a su edición del Charles Darwin's Beagle Diary, [1831-1836], op cit. El Journal of Researches... de 1839 permanece inédito en castellano.

En 1845 Charles Darwin hizo extensas revisiones al texto y cambió el orden de las palabras del título a Journal of Researches into the Natural History and Geology..., vendiendo los derechos de impresión ahora a John Murray, impresor de Londres. Esta edición familiar se ha difundido extensamente y traducido a muchos idiomas. En castellano ha sido titulada como Viaje de un naturalista..., y existen al menos tres traducciones distintas de la obra completa en nuestro idioma, incluyendo a la contenida en la edición argentina ilustrada de 1945, al cuidado de Joaquín Gil (El Ateneo, Buenos Aires).

11 Ver R.D. Keynes (1988). En este estudio emplearé la transcripción más moderna del Beaglés Diary de este investigador; todas las citas de esta fuente corresponden a mi traducción. 
En este examen daré completa preferencia al Diary, este registro espontáneo del propio Charles Darwin durante el viaje, que denominaré en adelante Diario. En el Diary se comprueba la decisión anterior del joven naturalista anterior de hacer un viaje a Sudamérica —impulsado por la lectura de Alexander von Humboldt- lo cual es mencionado en la Autobiografía y en la correspondencia. Darwin estaba por ello ya estudiando castellano, y en el Diary usa expresiones en este idioma incluso desde las páginas dedicadas al Brasil, para intentar capturar palabras o frases oídas en portugués. También usa varios italianismos - tanto en el Diario como en el Viaje-, quizá un testimonio de su temprana afición a la ópera, que también se deduce de la Autobiografía y de la correspondencia con las hermanas.

Habiendo empezado esta travesía con sólo 22 años, su autor calificó a su Diario - en las cartas a las hermanas - más como una colección de pensamientos — «thoughts» (y afterthoughts)—, que como un recuento de los acontecimientos del viaje. Él esperaba que los acontecimientos quedarían registrados más bien en el diario del capitán FitzRoy, publicado al final del viaje como segundo volumen de la Narrative... del mismo. Una parte de las anotaciones del Diario de Charles Darwin - y de otros borradores científicos elaborados a bordo por el naturalista- sirvieron de base al citado Journal of Researches... (1839) tomo tercero de la Narrative..., que como dijimos habría de convertirse luego en el Viaje... (1845).

Analizaremos en este trabajo y el siguiente, a partir de la fuente que puede utilizarse con más provecho para ello —el Diary—, el principio de la formación de Darwin como observador social $-\mathrm{y}$ sociológico- Luego de estos acápites de introducción, el trabajo dará la voz al entonces joven naturalista y autor, citando sus observaciones sociales durante su estadía en Bahía, entre el 29 de febrero y el 4 de marzo de 1832. Luego, bajo el rubro general de 'Consideraciones finales' viene la sección analítica, la cual habrá de ampliarse en el siguiente artículo sobre su estadía en Río de Janeiro. Esto porque - como veremos - la experiencia de Darwin en Bahía significó sólo su despertar en cuanto a la observación social.

\section{Darwin en el trópico. Las observaciones previas en Cabo Verde}

Durante la travesía misma, el joven Charles Darwin - cumpliendo los deberes de su puesto de 'naturalista oficial' en el H.M.S. Beagle - fue perfeccionándose en los hábitos de elaborar diversos tipos de registro científico de observaciones y especímenes colectados que le habían enseñado sus maestros en Cambridge, pero también se ocupó en escribir su diario personal. ${ }^{12}$ La prolongada espera para la partida del Beagle, debida al mal tiempo, le sirvió para empezar a soltar su pluma en él, y empezó a describir a la gente de los puertos de Devonport y Plymouth.

En general, Darwin había sido muy influenciado por la lectura de la Personal Narrative... de Alexander von Humboldt [1824-29]..$^{13}$ Esto no sólo en cuanto a la 'filosofía de la naturaleza' totalista que impregna aquella obra, sino también en aspectos ligados a la observación, a la larga quizá inclusive por la idea humboldtiana de que la observación del 'cuadro político y social' por el viajero científico no podía separarse de la observación de la naturaleza. La traducción en seis volúmenes de la obra del sabio alemán al inglés le había sido regalada a Darwin con una dedicatoria por su maestro y mentor en Cambridge, el naturalista John Stephen Henslow (1796-1861). En el Brasil Darwin pudo escribir muchas impresiones directamente en su Diario sin anotaciones previas en las libretas de apuntes. Los apuntes de tipo social en su mayor parte se escribieron en el Diario y no pasaron al Viaje en ninguna de sus dos versiones editadas.

Después de algunos intentos frustrados, el Beagle había partido de Plymouth el 27 de diciembre de 1831 rumbo a las Canarias, donde no se les permitió desembarcar por razones sanitarias. En la isla de Santiago, en el archipiélago de Cabo Verde -colonia portuguesa a 300 millas de la costa este africana- tuvo lugar la primera expedición de Darwin como naturalista en territorio extranjero, y su primer contacto con el trópico y la sociedad esclavista colonial portuguesa basada en el sistema de plantaciones.

12 El asunto de lo novedoso del puesto de Darwin en las naves de la marina británica y las discusiones que ha suscitado el tema entre sus estudiosos lo trata van Wyhe (2013).

13 El tema de la influencia y las relaciones entre Darwin y Humboldt es extenso e importante, y el contacto personal sucedió después del viaje y la publicación del Journal of Researches... y no puede ser desarrollado aquí. 
Estuvo fuertemente impresionado por la belleza del medio ambiente tropical, comparándose a sí mismo a un hombre ciego a quien se le hubiera concedido súbitamente la vista. Pero sobre todo lo impresionó el poder interpretativo de la geología de Lyell en la posibilidad de comprensión del lento levantamiento y de la formación geológica misma de la isla. Por ello rápidamente tomó allí una primera decisión literaria:

Se me ocurrió por primera vez que debería escribir quizá un libro sobre la geología de los diversos territorios visitados ([1876] 1958:81). ${ }^{14}$

Ahora bien, una de sus primeras observaciones humanas en Porto Praia — el puerto de la isla - lleva, sorprendentemente, por la importancia clasificatoria concedida a la vestuimenta, una fuerte impronta de un pensamiento de Antiguo Régimen:

El pueblo es un lugar miserable, consistiendo en una cuadra u algunas calles... En el medio de estas «Ruas» reposan juntas cabras, cerdos y nińos negros y pardos [black \& brown children]: algunos de ellos presumían de tener una camisa, pero muchos no: estos últimos se veían tan poco como como seres humanos que no podría haber imaginado otra degradación mayor (Darwin [1831-1836] 1988:23).

O quizá la observación esté entre las que después Darwin clasificó de «infantiles» (childish) en su Diario. El hecho es que la observación no es precisamente racista, pues por otro lado, durante su educación en Edinburgh el joven estudiante de medicina contrató como profesor particular de taxidermia -especialmente de aves - a John Edmonstone, un «...negro africano, creo que un antiguo sirviente del doctor Duncan", que preparaba ejemplares para el museo de Historia natural de la universidad, de quien escribió «...solía sentarme con él pues era un hombre muy agradable e inteligente» (Browne 2005: 108). Por ello no debe extrañar su posterior falta de prejuicios hacia

14 En efecto, el voluminoso manuscrito del llamado 'Geological Diary' o 'Diario Geológico', resultado de esta decisión, que permanece inédito, fue una de las fuentes principales que usó después, tanto para el Journal of Researches... publicado en 1839 como para los posteriores tres tomos de la Geology of the voyage of the Beagle [1842-1846]. El útil tercer volumen sobre la geología de Sudamérica ha vuelto a ser traducido al castellano en 2011 como parte de la Biblioteca Darwiniana promovida por el CSIC de España. la población de color durante el viaje. ${ }^{15}$ Comentando días después el encuentro con dos hombres de color en el interior de la isla, los cuales les venden leche de cabra, anota en el Diary:

Estos alegres hombres de corazón simple nos dejaron entre estruendosas carcajadas. - No he visto nada más inteligente que los negros [Negroes en el original], especialmente los niños negros o mulatos. - todos ellos inmediatamente percibieron y estuvieron sorprendidos de las armas de fuego. ellos examinan todo con la atención más vivaz y si dejas a los nińos cotorrear, sacarán todo fuera de tus bolsillos para examinarlo. - Mi caja de lápices de plata fue sacada fuera y se debatió mucho sobre ella. - (Darwin [1831-1836] 1988:26, subrayado en el original).

El 2 de febrero, en el interior de la isla conoce con sus compañeros de excursión a un hacendado portugués, quien les trata

...del modo más amable y nos agasaja con una sustancial comida hecha de carne cocinada con varias clases de hierbas y especies y [con] tarta de naranjas. - Este hombre es el poseedor principal de la plantación y aparentemente vive en una gran comodidad; su casa es simple, pero tiene quizá la felicidad utópica de ver crecer todas las cosas que necesita en su propio suelo (idem, 33).

Regresando a Porto Praia — donde se encuentra el Beagle - el grupo pasa por un poblado en plena fiesta:

...el poblado estaba lleno de gente. - a pequeña distancia alcanzamos a alrededor de veinte jóvenes negras. - vestidas con el más excelente gusto. - sus pieles negras y vestidos de lino blancos como la nieve estaban adornados con alegres turbantes coloreados y grandes chales. - Cuando nos aproximamos a ellas súbitamente todas se voltearon y cubrieron el camino con sus chales. - ellas cantaban con gran energía una arrebatada canción: llevaban el compás golpeando sus piernas con las manos. - Les arrojamos algo de vino, lo que recibieron con sonoras carcajadas, y las dejamos redoblando el ruido de su canción (idem).

15 Desmond y Morris han dedicado un libro a las convicciones antiesclavistas de Darwin y su familia, y han sostenido la influencia de estas ideas en su concepción de la evolución humana (2009). 
Así, en Cabo Verde Darwin no hizo aún las observaciones de tipo sociológico cuyo origen estamos rastreando, sino observaciones sociales de tipo más bien general - etnológicas en todo caso, y hasta estéticas - sobre los exóticos habitantes de color negro y sus patrones portugueses. En realidad se perfila aquí el hábil observador psicológico que llegó a ser Darwin, un asunto sobre el que volveremos en la parte analítica al final del trabajo.

\section{Darwin en el Brasil. Las observaciones sociales en San Salvador de Bahía}

El 29 de febrero de 1832, alrededor de las nueve de la mañana, se inició el viaje sudamericano y brasileño del naturalista con la llegada del Beagle a la bahía de Todos los Santos,

...en cuyo lado norte se encuentra el pueblo de Bahía o San Salvador. Puede ser difícil imaginar, antes de tal vista, algo tan magnífico. - Se requiere, sin embargo, la realidad de la naturaleza para hacer algo así. - Aunque fielmente representada en una pintura, un sentimiento de desconfianza se alzaría en mi mente, como pienso es el caso con algunas de las vistas de Martins.16 La ciudad está bellamente estampada en un exhuberante bosque y situada en un banco escalonado que vigila las aguas calmas de la gran bahía de Todos los Santos. /f.115/ Las casas son blancas y elevadas y por ser las ventanas delgadas y largas, tienen una apariencia muy ligera y elegante. Conventos, porticos [en castellano en el original] y edificios públicos varían la uniformidad de las casas: la bahía está salpimentada de grandes barcos; en resumen la vista es una de las más hermosas del Brasil (Darwin [18311836] 1988:41-42).

La ciudad había sido la capital de Brasil desde el siglo XVI hasta 1808 —en que D. Joao VI trasladó la corte portuguesa y la capital a Río de Janeiro- y tenía 60,000 habitantes en 1822 (Waddell 1985:319). En ella se había establecido una comunidad de comerciantes británicos que parecen haber sido por lo menos veintitrés en 1828. Para la década del 1830 ellos habían adquirido propiedades en el barrio de

16 En realidad se llamaba Conrad Maartens, artista holandés contratado como dibujante oficial a bordo.
Victoria, zona elegante en la parte alta de la ciudad de Bahia - y fundos en el interior- mientras despachaban sus asuntos en la populosa parte baja de la ciudad, alrededor de la larga calle denominada Rua da Praia. ${ }^{17}$

En cuanto a la coyuntura política y social, desde 1822 Brasil había llevado a cabo negociaciones con los británicos en busca del reconocimiento del reino independiente del Brasil. Hubo un pacto tácito: abolición de la esclavitud a cambio de ese reconocimiento. El 23 de noviembre de 1826 el emperador Dom Pedro I firmó un tratado según el cual el comercio de esclavos se declararía ilegal en Brasil tres años después de la ratificación. El ministro británico en Río Robert Gordon opinaba que el gobierno había aprobado «nuestra solicitud en contra del punto de vista y deseos de todo un imperio" y de que el tratado era «impopular al máximo» (citado en Waddell 1985:327).

Para inicios de la década de 1830 había una profunda crisis política de Brasil, consecutiva a las discusiones y la no decisión de un régimen político definitivo para la nación. La 'luna de miel' de D. Pedro I con la clase propietaria brasileña llegaba a un final. Además, el descontento de la plebe en las ciudades fue un elemento crítico adicional. La independencia había creado expectativas de mejora; cuando las condiciones de vida empeoraron, creció el resentimiento. A mediados de marzo de 1831 —cuando el emperador volvía a Río- estallaron luchas callejeras entre quienes le apoyaban, en su mayoría portugueses, y sus opositores. El 7 de abril D. Pedro I abdicó a favor de su hijo D. Pedro II —demasiado joven para gobernar-y decidió regresar a Portugal, iniciándose el período de la regencia (idem, 330).

La abdicación del emperador sacudió todo el Brasil. En la segunda ciudad más importante de Brasil — Salvador de Bahia - durante 1831 y 1832 hubieron por lo menos seis levantamientos de milicia y pueblo llano (idem, 332). Se produjo asimismo la llamada 'guerra de los Cabanos', de 1832 a 1835, restauracionista y en la que participaron incluso pequeños terratenientes (idem). La regencia formó una

17 Un magnífico panorama de la independencia y primer período independiente del Brasil en Bethell (1985) y Waddell (1985), que seguimos en esta parte. Los datos de la comunidad comercial británica en Bahía los mencionamos según la investigación preliminar de Guenther $(2001: 4,15)$. 


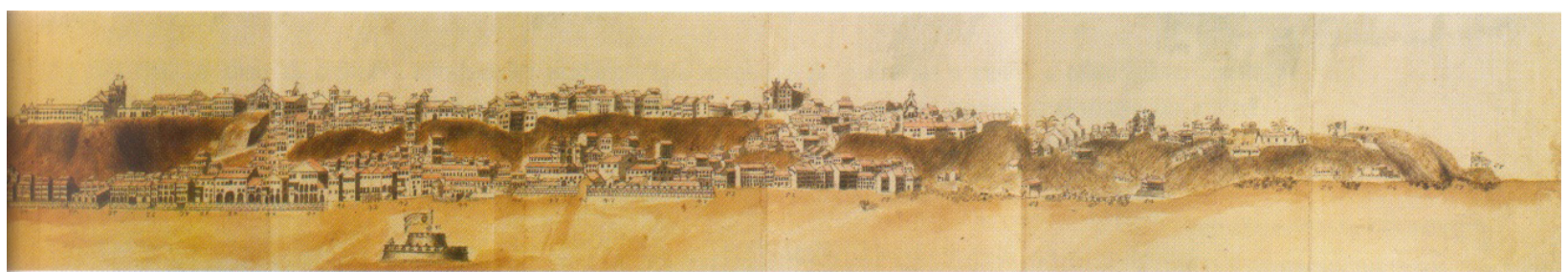

Figura 4. Sección de una vista panorámica de San Salvador de Bahia vista desde el mar por Vilhena (principios del siglo XIX), que se conserva en la Biblioteca Nacional de Rio de Janeiro. Reproducida de Borges (2008:25).

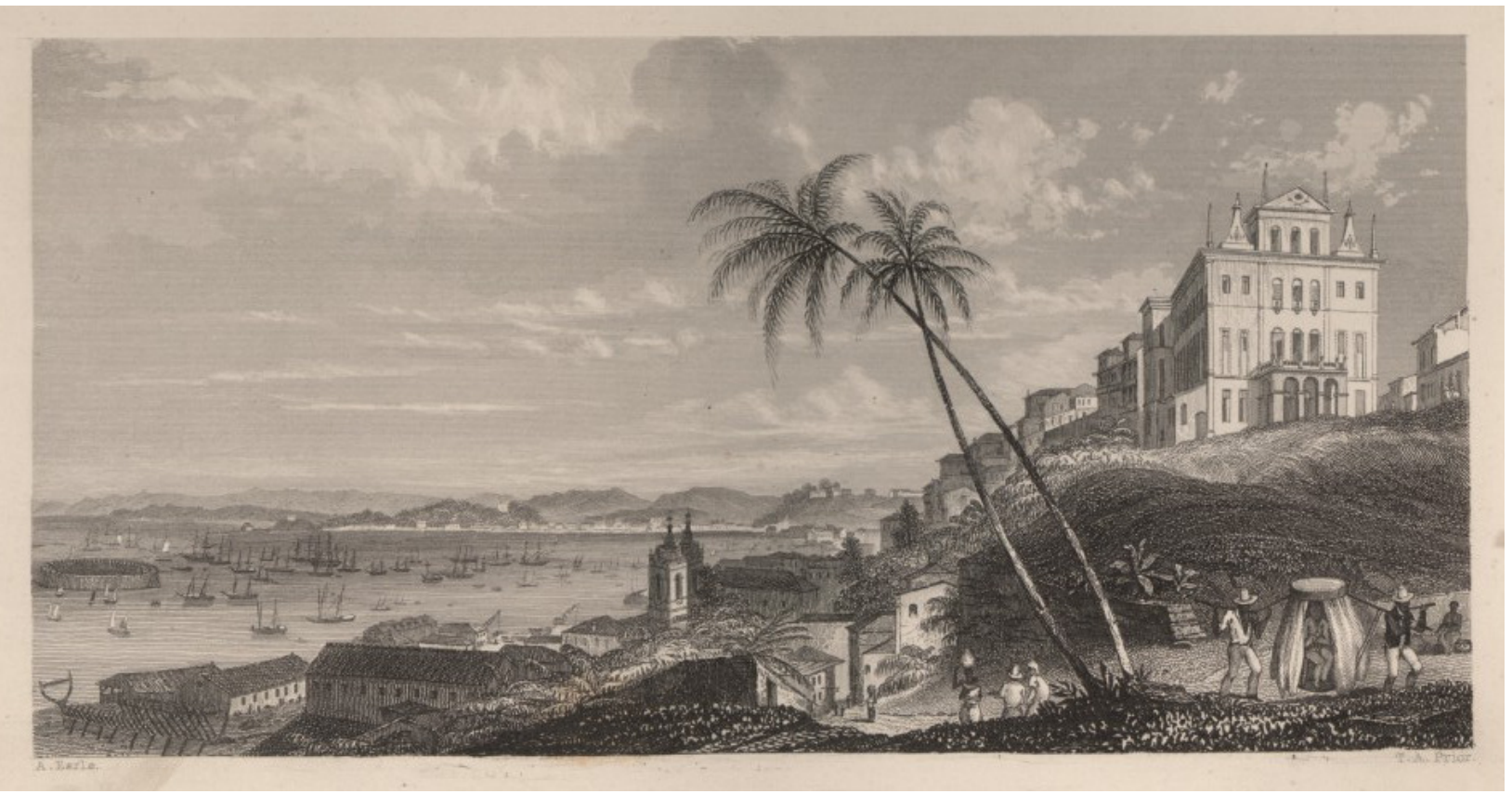

Figura 5. Grabado de la ciudad y la bahía de San Salvador, basado en un dibujo de Augustus Earle, dibujante del Beagle. Incluido en la Narrative... de FitzRoy, t.2, p.62.

Guardia Nacional y lo cierto es que el Brasil era ahora de la clase propietaria tradicional brasileña.

En esta situación política y social algo inestable Inglaterra continuó ejerciendo la tutela obtenida mediante el célebre 'secuestro' de la corte, y cuidando sus intereses comerciales en Brasil. La situación de principios de 1832 no afectó así aparentemente las labores del HMS Beagle. Charles Darwin no escribió comentarios políticos en su Diario, pero pronto notará la tensión y consecuencias derivadas de la situación de los esclavos negros. Al principio de su estadía escribe más bien que para él las bellezas urbanas de Bahia «...no son nada comparadas con la vegetación» (Darwin ([1831-36]1988:40) y en las cercanías de la ciudad, deslumbrado, observa por primera vez el bosque tropical. El impacto que le produce está entre los episodios más tratados del viaje, por lo que no nos detendremos en él para concentrarnos en las observaciones humanas y sociales:

He estado vagabundeando /f.116/ solo en un bosque brasileño: entre la multitud de objetos es difícil decir cuál es más sorprendente: la espléndida vegetación se lleva la victoria... (idem, 42$).{ }^{18}$

En medio de su absorta observación experimenta su primera tormenta tropical y al día siguiente, $1^{\circ}$ de marzo de 1832, penetra algunas millas a pie en el interior y anota que "...lleno de alegría uno desea fervientemente vivir en retiro en este nuevo y más grande mundo». El 2 y 3 está detenido por la fuer-

18 La impresión que le causó el bosque tropical brasileño es tratada por ejemplo en Desmond y Moore (1991:119) y pueden verse las poéticas expresiones del naturalista al respecto en el Diary ([1831-36]:1988:42-43). 
te lluvia, pero también dice experimentar la simple 'ociosidad' inducida por el cálido clima (idem, 43). El mismo 3 de marzo visita la ciudad, que

...en la parte baja cerca al muelle tiene las calles muy estrechas y las casas aún más altas que en el viejo centro de Edinburgh. El olor es muy fuerte y desagradable, lo cual no es de asombrarse, pues observo que tienen la misma necesidad de gritar «¡cuidado con el agua!» [en francés en el original] que en /f.118/ Auld Reekie ${ }^{19}$. -

Pero anota por primera vez una serie de observaciones sobre el trabajo y el régimen de trabajo en Bahia:

[...t] odo el trabajo es hecho por los hombres negros, que permanecen agrupados de pie alrededor de los almacenes comerciales. - Las discusiones que se hacen sobre la cantidad de contratos son muy animadas; los negros ${ }^{20}$ en todo momento usan mucha gesticulación y clamor y cuando se tambalean bajo sus pesadas cargas, cuentan el tiempo y se alientan a sí mismos mediante una ruda canción. - Sólo he visto un carro de ruedas; pero los caballos no son de ninguna manera escasos; son generalmente pequeños y bien formados y son principalmente usados para cabalgar por los mercaderes. - [...] Mr. Gond, uno de los principales mercaderes del lugar, ofreció alquilarnos caballos si quisiéramos ir a su casa de campo. - Aceptamos honrados su oferta y disfrutamos la más deliciosa cabalgata; una hermosa vista sucedía a la otra en una sucesión sin fin (idem, 43).

El día 4 de marzo es «...el primero del Carnaval, pero Wickham, Sullivan y yo mismo, [aunque] nada impertérritos, estamos determinados a encarar sus peligros.- " (idem). Ellos consisten en

...ser bombardeado sin piedad con bolas de cera llenas de agua y ser totalmente bañado con grandes baldes de latón. - Encontramos muy difícil mantener nuestra dignidad mientras caminábamos a través de las calles. - [...] Digo que [es un hombre valiente] quien puede caminar a un paso regular cuando baldes de agua están listos a caer sobre él a cada lado [de la calle]. Después de algunas horas

19 Un barrio de Londres conocido para Darwin y su familia, la primera destinataria del Diario.

20 En estas dos primeras referencias Darwin usa blackmen en la primera y Negroes en la segunda. maniobrando por el territorio peligroso, al final alcanzamos el campo y allí estábamos bien determinados a permanecer hasta que fuera oscuro. - Así lo hicimos, y tuvimos alguna dificultad en encontrar el camino de vuelta, pues tuvimos cuidado en volver por la costa a las afueras del pueblo. - Para completar nuestras ridículas miserias una fuerte lluvia nos empapó totalmente y finalmente alcanzamos orgullosamente el Beagle.- (idem, 43-44).

Luego de hacer colectas de especímenes el día 5, posiblemente habiéndose golpeado, Darwin sufre la inflamación de una rodilla, por lo cual —impedido de caminar-, descansa en su hamaca del Beagle hasta el 12 de marzo. Anota nuevamente: «[n]o estoy nada sorprendido de que la gente sea así de indolente en un país cálido; ni la mente ni el cuerpo requieren ningún ejercicio; observar el cielo parece suficiente ocupación para la primera...» (idem, 44).

En esos días de obligada permanencia en el Beagle sucede un incidente interesante para nuestros propósitos. FitzRoy - aunque supuesto adversario de la esclavitud- argumenta que ella no es intolerable en Brasil, pues los colonos en general tratan a sus esclavos bien. Pero, como remarcan Desmond y Morris - a quienes seguimos en la reconstrucción de este incidente-, «...la esclavitud era la única institución que toda [la] familia [de Darwin] había abominado. Era el mal puro, y Darwin sugiere que la única solución era la emancipación» (1991:120). El capitán se irrita, y afirma haber oído a un propietario de esclavos preguntar a sus sirvientes si ellos eran infelices o deseaban ser libres. "No», habrían replicado, y FitzRoy añadía si sus deseos no debían ser respetados. Darwin se pregunta si la respuesta de un esclavo en presencia de su patrón vale como testimonio. Atrapado, FitzRoy —apodado 'Café caliente' por la tripulación- explota, declarando que ellos no pueden convivir juntos más, que su palabra había sido cuestionada y se retira abruptamente de la cabina.

Los oficiales invitan a Darwin a juntarse con ellos en la sala de armas y le cuentan sobre las alzas y bajas en el ánimo del sensible aristócrata. Pocas horas después FitzRoy le envía una disculpa y le pide continuar siendo su compañía en la cabina de capitán y la mesa (idem). Ese mismo día visita el Beagle el Capitán Paget, del HMS Samarang, y por él se entera Darwin - en presencia de FitzRoy-, de las realidades del comercio esclavista en el Brasil: 
...él [Paget] ha mencionado en presencia de quienes podrían haberlo contradicho de haber podido, hechos sobre la esclavitud tan inquietantes, que /f.122/ de haberlos leído en Inglaterra, [yo] los habría derivado hacia el celo de la gente bien intencionada [en estos menesteres]: La extensión en la cual el comercio [de esclavos] es llevado a cabo; la ferocidad con que es defendido; la gente respetable (i!) [sic] que está implicada, todo está lejos de ser exagerado en Inglaterra. - No dudo que el estado actual de gran parte de la población esclava es mucho más feliz de lo que uno previamente se habría inclinado a creer. El interés y los buenos sentimientos del [de los] propietario[s] podrían tender a esto. - Pero es profundamente falso (como ha probado satisfactoriamente el Cap. Paget) que ninguno, aún el mejor tratado, no desee retornar a su país. - «Si yo pudiera ver a mi padre y mis dos hermanas una vez más, sería feliz. Nunca puedo olvidarlas». Tal fue la expresión de uno de ellos, quienes son clasificados por los pulidos salvajes en Inglaterra como hermanos. - Por ejemplo he visto gente tan ciega y obstinadamente prejuiciosa, a quien en otros puntos se puede dar crédito, que sobre este punto no deberé descreer tan profundamente: Hasta el punto donde puedo dar testimonio, cada individuo /f.123/ que tiene la gloria de haberse ejercido en el asunto de la esclavitud [sic], puede contar con que sus trabajos son ejercidos contra miserias quizá aún mayores que las que él imagina. - (idem, 45).

A partir de entonces el naturalista tendrá los ojos más abiertos a la esclavitud - y a todo lo que se deriva de ella-, como veremos después en sus notas sobre Río de Janeiro. El 14 de marzo retorna a hacer sus colectas, y el 15, en las afueras de Bahía, ingresa en una venta y, mientras bebía con sus acompañantes «...el más excelente Sangaro» (combinación de vino, agua y azúcar),

[c] omo suele suceder generalmente, fuimos rodeados por hombres negros, mujeres y niños. Yo no sé si les resultaba el más divertido; su asombro fue grande al ver la red para insectos, la pequeńa pistola y el compás: conforme una cosa salía tras otra de mis bolsillos más grandes, ellos gritaban «lleno, lleno de pecados». - Sin duda pensaban /f.124/ que todos mis instrumentos estaban relacionados «al Diabolo». - Todo el mundo queda encantado con los excelentes modales de los negros. - Di a mis amigos en la venta algún vino, y cuando lo compartía, es mi firme convicción que ninguna duquesa con tres colas [en el vestido] podría haber dado tales dignas y cortesanas reverencias como las mujeres negras cuando me saludaban [al beber]. - (idem, 46).

Se reafirma pues en su simpatía a la población de color y — como miembro de la gentry—, se fija incluso en sus modales. En los dos días siguientes realiza algunas colectas más de animales y plantas en los alrededores de la ciudad y el 17 de marzo se despide de Bahía, señalando en un primer balance que

Si a lo que la naturaleza ha otorgado al Brasil el hombre ańade sus justos y propios esfuerzos, ¡ de qué [gran] país pueden los habitantes alardear! Pero la mayor parte está bajo un estado de esclavitud, y donde este sistema es mantenido con un completa detención de la educación, la principal fuente de las acciones humanas, esto causa lo que puede ser esperado; y el todo puede ser contaminado por esta parte. - /f.126/ (idem, 46, mis subrayados).

Que esto era así es algo que él mismo averiguará después en Río, como veremos en un próximo trabajo. Por ahora, el 18 de marzo el Beagle abandona Bahía, y navega durante nueve días por la costa de Brasil. Llegan a las islas de Abrolhos, donde deben hacer algunos sondeos marítimos durante tres días, que Darwin aprovecha para recolectar especímenes. El día 3 de abril bordean el llamado Cabo Frío y recorren la costa, «...irregularmente montañosa y salpicada de colinas [morros] de formas singulares» (idem, 49, mi traducción). "La entrada del puerto [de Río de Janeiro] es distinguible por una de ellas, el bien conocido Pan de Azúcar» (idem).

\section{Consideraciones finales}

Lejanos están los días en que Darwin podía ser retratado como un visionario, un genio fuera de su tiempo (Desmond y Moore:1991:xx).

Los afanes intelectuales de la familia [Darwin/ Wegwood], junto con su posición social profesional, cortés escepticismo religioso, alto nivel de educación, habilidad comercial y opiniones políticas liberales, obtuvieron que Charles Darwin siempre ocupara un lugar en la sociedad británica intelectual tanto como el prospecto de una cómoda herencia financiera. Ambos fueron factores materiales en sus logros posteriores (Browne 2017:17). 
En primer lugar hay que decir que la posición social de Darwin en la nave y en el viaje - que es un asunto importante en el análisis de su punto de vista-, se derivaba de su condición de gentleman - es decir miembro de la gentry, clase burguesa ascendente propietaria de tierras en Inglaterra-, de tendencia política mayormente whig o liberal. «Él era la única persona a bordo, por ejemplo, que podía dirigirse al capitán FitzRoy por su apellido en la forma cercana de los amigos íntimos» (Browne 2005: 274). El apellido Darwin era conocido debido a su abuelo Erasmus — famoso autor naturalista- y a su padre Robert, médico y financista afortunado. Estos factores y su carácter afable - junto a su preparación en geología-, determinaron su elección como naturalista y acompańante de mesa por el conservador y problemático FitzRoy. Éste y la tripulación le tomaron carińo durante el viaje, apodándole 'Philosopher' o 'Philos', pero había ocasionalmente puntos de desacuerdo con el capitán, que Darwin aprendió a eludir con diplomacia.

La labor de naturalista extranjero y los salvoconductos que pusieron a disposición de Darwin la Marina y la naciente diplomacia británicas en Sudamérica - para que recorra sobre todo regiones inexploradas de Argentina, Uruguay y Chile-, le permitieron ponerse en contacto con gran variedad de gente durante la travesía. Por citar sólo Argentina, allí trató desde indios fueguinos, pampeanos, gauchos y militares del ejército de Rosas - y al propio Rosas - en la pampa argentina, hasta a los educados españoles y criollos y sus mujeres en Buenos Aires, por sólo citar los tipos sociales más destacables.

En Brasil, donde estuvo menos tiempo, la experiencia no incluiría a los indios brasileños ni a la corte remanente en Río, y en general trató menos a la clase criolla propietaria de origen portugués. Esto último debió suceder porque la 'tutela' inglesa sobre el Brasil -sumamente ventajosa para el comercio inglés, que gozaba incluso de tarifas impositivas preferencialesno era bienvenida para las clases altas. Había transcurrido ya buen tiempo desde la firma del comercio libre al gusto de los ingleses por D. Joao VI en 1808, una de sus primeras medidas, efectuada como vimos al llegar a Brasil custodiado por las naves británicas (Fausto, 1999, Bethell 1985). En general, como vimos, se trataba de un período de inestabilidad política y social — la llamada 'regencia'-, con frecuentes levantamientos en el interior. Además estaba el hecho de no ser los ingleses católicos, que era - como vimos - claro hasta para los niños negros, que en el pasaje antes citado del Diary los relacionaban al diablo y al pecado, pero ciertamente no eran los únicos en hacerlo en la sociedad brasilera de la época.

En un aspecto poco o nada destacado en la literatura sobre el viaje del Beagle, es observable la rápida percepción del joven Darwin de las posibilidades económicas de las regiones visitadas —una cuestión que probablemente venía de suyo entre los miembros de su clase social pasada la adolescencia- y que es más perceptible en las notas sobre el interior de Río de Janeiro. Podemos notar que sus observaciones de tipo etnológico y aún psicológico preceden a las de tipo propiamente sociológico, que son las que interesan más al historiador y al científico social. De hecho, la etnografía de Darwin empezaría en el propio H.M.S. Beagle, donde observó y trató detenidamente a los nativos Yahgan que la nave llevaba a bordo de regreso a la Tierra del Fuego, de donde fueron llevados a Inglaterra por Robert Fitzroy durante el primer viaje. Pero su etnografía no se puede separar de una observación de las capacidades mentales y la psicología de los observados. En este tipo de observación adivinamos también ya elementos para una argumentación como la de Desmond y Morris (2009) sobre los orígenes de las ideas de la evolución humana del naturalista británico.

En cambio, la percepción de los rasgos de organización interna de las sociedades visitadas y de sus tipos sociales -incluidos los de la población general-, es decir, su habilidad para la descripción sociográfica y el análisis de tipo sociológico es algo que vemos que el joven naturalista va adquiriendo de a pocos - aunque rápidamente- y algo que defendemos aquí que justamente sucedió en su mayor parte durante el breve paso por el Brasil. Terminaremos de demostrar esto en el siguiente trabajo, pues esta formación terminó de suceder en Río de Janeiro. Tenemos la suerte de que anotó esta clase de observaciones sociológicas en su Diario de viaje. Comentó las primeras fases de la escritura de este testimonio en cartas a sus hermanas - las primeras dedicatarias del Diary_- pues el documento empezó también como un modo de conservar los lazos con el hogar distante.

En efecto, al remitirles los primeros grupos de hojas del Diary — apenas salido de Brasil, en abril 
de 1832-, Charles se disculpa ante su hermana Caroline, diciéndole que

Me ha producido un ataque de disgusto, y quiero tenerlo lejos de mi vista... . - una gran parte es absolutamente infantil... (citado en la introducción del editor Keynes a Darwin [1831-1836]1988:xv).

En noviembre agregaría a Caroline «...sospecho que la primera parte es abominablemente infantil» (idem, xvi). Probablemente se refería a ser algo exaltado en su prosa de naturalista e intentar imitar las descripciones poéticas de Humboldt. ${ }^{21}$ Nosotros podemos señalar aquí lo estético y algo idealizado de sus primeras observaciones de la población negra en Cabo Verde, así como la sorprendente observación sobre los niños 'de color' sin camisa y sus ya citadas perspicaces observaciones sobre los modales y 'majestuosidad' de la gente de color con quien se cruza en el campo y las ventas o vendas en el interior de Bahia.

Precisamente el tránsito cualitativo en el tipo de observación social de Darwin lo marca su percepción de las condiciones de trabajo de los esclavos en las afueras de las casas comerciales en el barrio comercial de Bahia y la indagación posterior que provoca en él. El joven de veintitrés ańos observa que existen buenos carros y caballos, pero los esclavos cargan todo en sus espaldas. Esto - probablemente deduce - se debe al bajo precio de los esclavos, que encuentra causado por el aún boyante tráfico de esclavos. La detención en sus actividades de naturalista debido a una inflamación en la rodilla le hace conversar del asunto con FitzRoy, como vimos, y la defensa imposible de éste del buen trato y felicidad en que viven los esclavos del Brasil le llevan a un comentario irónico — que basta para hacer estallar la rabia en el sensible capitán aristócrata del Beagle-. ${ }^{22}$ Esto a su vez le lleva a informarse - como vimos - por una fuente más neutral, el capitán de otra nave con igual experiencia del país.

Su indignación al enterarse por el capitán Paget de la magnitud del tráfico de esclavos muestra bien

21 Las hermanas le señalaron algunos de estos defectos iniciales, lo animaron a que usara su modo directo y espontáneo de escribir y a que debía continuar escribiéndolo, manifestándose encantadas por las noticias transmitidas por su hermano. Una contextualización y una defensa de una sensibilidad romántica en Darwin en Kohn (1996).

22 Darwin recordaba bien el incidente hasta en su Autobiografia de 1874, pues no los hubo tan marcados durante el resto del viaje, y es significativo que hubiese tenido por motivo un intercambio de pareceres sobre la esclavitud en el Brasil. la formación que había recibido en este punto en su familia y su posición política whig o liberal. Podemos traer a colación aquí la precisa afirmación de su biógrafa Janet Browne respecto a que

Charles Darwin mismo no adoptó ninguna ideología obvia, excepto quizá la del abolicionismo anti-esclavista... [Pero] [d] esde su nacimiento él absorbió la ideología prevaleciente de progreso industrial y colonial (2017:15-16).

La arriba citada reflexión final de su Diario en Bahia, respecto a que «...el todo [social] puede ser contaminado por esta parte [la esclavitud]» es sorprendentemente aguda y madura para un joven de veintitrés años. Lo veremos confirmándola — desde su punto de vista - en su paso por Río de Janeiro y su interior, y creemos que esta observación marca bien el comienzo de la maduración de Darwin como agudo observador social a observador de tipo sociológico, que hemos encontrado en esta investigación que fue prácticamente simultánea a la que adquirió en el viaje sudamericano como geólogo y naturalista.

\section{Nota}

La investigación para el presente artículo - y el que le sigue - sobre Charles Darwin como observador social en el Brasil se ha desprendido de una investigación sobre la estadía de Darwin en el Perú (1835) (Arana Bustamante, ms. 2017). Encontramos útil comparar esta visita con la del Callao y Lima por la cortedad de ambas, ciertas semejanzas sociales entre ambos países y por tener quien escribe la experiencia de haber visitado el Brasil (Río de Janeiro). Se han publicado adelantos y partes de esta investigación en 'Sobre la estadía de Darwin en el Perú (1835). Un avance de investigación', Investigaciones Sociales 36:16-20, 2016; 'I extracted these remains by digging a hole...: Charles Darwin, protoarqueólogo en Lima [1835]. Un avance de investigación', Yungas 3:5-10, 2017; 'Celebrando el día internacional de Darwin 2018', folia darwiniana 3:7-12; 'Darwin en el Perú (1835): un panorama de los primeros días', folia darwiniana 3:27-38; y 'Tres cartas de Darwin enviadas desde Lima (1835)', Historia y Cultura 29:99113, 2018, del Museo Nacional de Antropología e 
Historia de Pueblo Libre. Por otro lado, en relación a este proyecto hemos lanzado en 2016 la publicación folia darwiniana, boletín de difusión electrónico disponible en la página del editor en www.academia. edu, boletín que aparece en febrero y noviembre, y del que se prepara actualmente el cuarto número.

\section{Bibliografía}

\section{Fuentes primarias}

Darwin, Charles ([1831-1836] 1988). Charles Darwin's Beagle Diary. Edited by Robert Darwin Keynes. Cambridge:Cambridge University Press.

Darwin, Charles ([1831-1836] 1987). Charles Darwin's Notebooks, 1836-1844. Geology, Transmutation of Species, Metaphysical Enquiries.Transcribed and edited by Paul H. Barrett, Peter J. Gautrey, Sandra Herbert, David Kohn and Sydney Smith. LondonCambridge:Natural History Museum, LondonCambridge University Press.

DARWIN, Charles [1839]. Journal of Researches into the Geology and Natural History of the various Countries visited by H.M.S. Beagle under the command of Captain FitzRoy, R.N. [Royal Navy] from 1832 to 1836. London:Henry Colburn.

Darwin, Charles, ed. [1839-1840]. The Zoology of the Voyage of H.M.S. Beagle under the Commandof Captain FitzRoy, R.N. [Royal Navy] from 1832 to 1836. London:Smith, Elder and Co.. 5 volúmenes realizados por diferentes autores.

DARWIN, Charles ([1845] 1942). Viaje de un naturalista alrededor del mundo. Tr. de J. Beaumont, edición al cuidado de Joaquín Gil. Buenos Aires:El Ateneo.

Darwin, Charles [1846]. Geological Observations on South America. Being the Third Part of The Geology of the Voyage of The Beagle under the Command of Capt. FitzRoy, R.N. during the years 1832-1836. London:Smith, Elder and Co.

DARWIN, Charles ([1846] 2011). Observaciones geológicas en América del Sur, edición de Rafael Sagredo Baeza, introducción de Rafael Sagredo Baeza y Francisco Hervé Allamand, traducción de María Teresa Escobar. Madrid: Catarata - Consejo Superior de Investigaciones Científicas - Universidad Autónoma de México DIBAM - Centro de Investigaciones Diego Barrós Arana - Editorial Universitaria.
Darwin, Charles ([1876] 1958). The Autobiography of Charles Darwin 1809-1882. With original omissions restored. With an Appendix and notes by his granddaughter Nora Barlow. London: Collins.

Humboldt, Alexander von ([1824-1829] 1966). Personal Narrative of Travels to the Equinoctial Regions of the New Continents during the Years 1799-1804. Translation of Helen Maria Williams. London. Reimpresión facsimilar: New York, American Press.

NARRATIVE..., V.2 [1839]. Narrative of the surveying voyages of His Majesty's Ships Adventure and Beagle, between the years 1826 and 1836, describing their examination of the southern shores of South America, and the Beagle's circumnavigation of the globe. London:Henry Colburn.

Turnbull, John [1813]. A Voyage Round the World in the Years 1800,1801,1802,1803 and 1804, in which the Author Visited Madeira, the Brazils, Cape de Good Hope, the English Settlement at Botany Bay and Norfolk Islands in the Pacific Ocean. Second Edition. London:E. Maxwell.

WyHE, John van (ed.), (2009). en adelante. The complete work of Charles Darwin Online, www.darwin-online. org.uk

\section{Estudios secundarios}

Arana Bustamante, Luis, ms. (2017) Darwin en el Perú (1835). Un estudio en historia biográfica y social. 175 pp.

Barlow, Norah (1933). Preface y Dramatis Personae. En Charles Darwin's Diary of the Voyage of H.M.S. Beagle. Edited from the MS [manuscript] by Norah Barlow, VII-XXIII. New York / Cambridge: The MacMillan Company / Cambridge University Press.

BArlow, Norah (1945). Introduction. En su Charles Darwin and the Voyage of the Beagle. London:Pilot Press.

BAYLY, C.A. (1989). Imperial meridian: the British empire and the world, 1730-1830. London-New York:Longman.

Bethell, Leslie (1985/1991). La independencia de Brasil. En Leslie Bethell, ed., Historia de América Latina, 5:171-203. Barcelona: Crítica.

Borges, Eduardo (2008). Primera parada [de D. Joao VI]. Revista de Historia da Biblioteca Nacional 28:22-25

BROwNE, Janet (1989). A science of empire: British biogeography before Darwin, Revue des Historie des Sciences, 45(4):453-475. 
Browne, Janet (1995/2009). Charles Darwin: una biografí. Volumen 1: De viaje. Traducción de Julio Hermoso. Valencia:Universitat de València.

Browne, Janet (2006). Darwin's Origin of Species: A Biography. London:Atlantic Books.

Browne, Janet (2017). Charles Darwin y la ideología. Repensando la revolución darwiniana. folia darwiniana 2:15-27. Traducción de artículo aparecido en Mètode 7. Science Studies Journal (2016). Universitat de València.

CaIn, P. y A.G. Hopkins, eds. (2002). British Imperialism 1688-2000. Cambridge:Cambridge University Press.

Darwin, John (2009). The Empire Project. Rise and Fall of the British World-System, 1830-1970, Cambridge: Cambridge University Press.

Darwin, John (n.d.). Widening the Gap: British Imperialism and the Great Divergence, 1830-1880.

Darwin Keynes, Robert (1988). Introduction a Darwin [1831-1836] 1988, XI-xxiv.

Desmond, Adrian y James Moore (1991). Darwin. The Life of a Tormented Evolutionist. New York - London:Norton.

Desmond, Adrian y James Moore (2009). Darwin's Sacred Cause: Race, Slavery and the Quest for Human Origins. London: Allen Lane/Houghton Mifflin.

ELDRIDGE, Colin C. ed. (1984). British imperialism in the nineteenth century. Basingstoke:Macmillan.

Fausto, Boris (1999). A Concise History of Brazil. Cambridge:Cambridge University Press.

Flores Galindo, Alberto (1979). El militarismo y la dominación británica (1825-1845). En AA.VV., Nueva Historia general del Perú. Un compendio, 107-121. Lima:Mosca Azul.

Ghiselin, Michael (2009). Darwin. A Reader's Guide. Occasional Papers of the California Academy of Sciences No. 155. San Francisco, CA: California Academy of Sciences.

Guenther, Louise (2001). The British Community of 19th century Bahia: public and private lives. Working Paper CBS 32-02. Oxford:University of Oxford Centre for Brazilian Studies.

KoHn, David (1996). The Aesthetic Construction of Darwin's Theory. En A.I. Tauber, ed., The Elusive Synthesis: Aesthetics and Science, pp. 13-48. Dordrecht-Boston-London:Kluwer.
Leakey, Richard E. and Roger Levin (1977). Origins. What New Discoveries Reveal about the Emergence of Our Species and its Possible Future. New York:Dutton.

Miller, Rory (1993). Britain and Latin America in the Nineteenth and Tweintieth Century. Liverpool:University of Liverpool Press.

NúŃEz HaGue, Estuardo (1989). Viajes y viajeros extranjeros por el Perú. Apuntes documentales con algunos desarrollos histórico-biográficos. Lima: Concytec.

Passetti, Gabriel (2014). O Brasil no relato de viagens do comandante Robert FitzRoy do HMS Beagle, 1828-1839. História, Ciências, Saúde - Manguinhos 21(3):911-930.

Quammen, David (2009). Las primeras pistas de Darwin. El bicentenario de Darwin. Primera parte. National Geographic (en español), febrero de 2009, pp. 2-21.

RookmaAker, Kees (2009). Darwin's itinerary on the voyage of the Beagle'. En Wyhe, John van (ed.), The complete work of Charles Darwin Online, www.darwinonline.org.uk

Stоскwell, Stuart (2008). The British Empire: Themes and Perspectives. Oxford:Oxford University Press.

Sulloway, Frank (1982). Darwin's conversion: The Beagles's voyage and its aftermath, Journal of the History of Biology, 15(3): 325-396.

TAYlor, I (2008). The Voyage of the Beagle: Darwin's Extraordinary Adventure in Fitzroy's Famous Survey Ship. London: Conwan.

Thomson, K. S. (1975). H.M.S. Beagle, 1820-1870, American Scientist 102, (1975), 218-225.

WADDELL, D.A.G. (1985/1991). La política internacional y la independencia latinoamericana. En Leslie Bethell, ed., Historia de América Latina, 5:209-233. Barcelona: Crítica.

WyHE, John van (2013). "My appointment received the sanction of the Admiralty": Why Charles Darwin really was the naturalist on HMS Beagle.Studies in History and Philosophy of Biological and Biomedical Sciences. En prensa.

WyHE, John van (ed.), 2004 en adelante, The complete work of Charles Darwin Online, www.darwin-online. org.uk 